\title{
CD117 Expression in Squamous Cell Carcinoma of the Oesophagus
}

\author{
LUIS FERNANDO MOREIRA, MARCELO MARAFON MAINO, \\ HENRIQUE IAHNKE GARBIN, GABRIELLA RICHTER DA NATIVIDADE, \\ BERNARDO SILVEIRA VOLKWEIS and JANE ULBRICHT KULCZYNSKI
}

\author{
Southern Surgical Oncology Group, HCPA University Attached Hospital, Faculty of Medicine, \\ Rio Grande do Sul Federal University, Porto Alegre, Brazil
}

\begin{abstract}
Background/Aim: Identification of changes in specific genes may help new attempts in finding targeted therapy for oesophageal cancer which still has a very poor prognosis. The aim of this study was to investigate CD117 expression in squamous cell carcinoma of the oesophagus (SCCO). Materials and Methods: A preliminary study was performed for CD177 immunoreactivity using a monoclonal antibody against CD117 on 27 SCCO specimens from patients who underwent surgical resection. Specimens of oesophageal mucosa obtained from 10 healthy individuals were studied as a control group. Results: Most patients had TNM American Joint Committee on Cancer stage IIb or III SCCO and mean overall survival was 21 (range $=2-72$ ) months. Cytoplasmic membrane CD117 immunoreactivity was demonstrated in only four (15\%) out of 27 tumours and in none of the controls. Conclusion: Although immunohistochemical expression of CD117 was higher than previously demonstrated, the lack of expression does not warranty further use in targeted therapy of SCCO.
\end{abstract}

Squamous cell carcinoma of the oesophagus (SCCO) is a highly aggressive neoplasm. Statistically, oesophageal carcinoma is the sixth leading cause of cancer-related death worldwide (1). The incidence varies geographically, with highest rates found in developing countries, such as Southern and Eastern Africa and Eastern Asia (2, 3). In southern Brazil, in the state of Rio Grande do Sul, SCCO may reach an estimated incidence of 16.21 and 4.21 new cases/100,000 men or women in 2018 (4).

Correspondence to: Luis F. Moreira, MD, Southern Surgical Oncology Group, HCPA University Attached Hospital, Faculty of Medicine, Rio Grande do Sul Federal University, Ramiro Barcelos 2350, $7^{\circ}$ Andar, Sala 735, Porto Alegre, RS, Brazil. E-mail: lufmoreira@hcpa.edu.br

Key Words: Oesophageal cancer, squamous cell carcinoma, CD117, carcinogenesis, immunohistochemistry, oncogenes.
At diagnosis, the majority of patients have locally or regionally advanced disease or disseminated cancer, which confers a poor prognosis (5). The underlying reasons for this disappointingly low survival rate are multiple: ineffective screening tools, cancer detection at an advanced stage, high risk for recurrent disease after oesophagectomy, definitive chemoradiotherapy, mutation of tumour-suppressor genes leading to reduced response to therapy and limited survival achieved with isolated palliative chemotherapy for patients with metastatic or unresectable disease (6). Surgical treatment has traditionally been the choice for patients with resectable tumours $(7,8)$. The combined modality approaches of chemotherapy, radiotherapy, and chemoradiotherapy with surgery have not led to a significant improvement in overall survival rate (9-12).

Several risk factors for development of oesophageal carcinoma have been identified, such as smoking and alcohol consumption, but the molecular mechanisms related to oesophageal carcinogenesis remain under investigation. Changes in specific genes that play important roles in several cellular functions such adhesion, signal transduction, differentiation or DNA development and repair, as well as apoptosis, have been identified (8, 13-15).

CD117 (c-KIT) is a transmembrane tyrosine kinase that acts as a receptor for stem cell factor or KIT ligand. It belongs to the type-III family of receptor kinases and it can be detected in several normal cell types including hematopoietic cells, germ cells, interstitial cells of Cajal, ductal breast epithelium, mast cells and melanocytes (16-18). This molecule is also consistently expressed in a number of tumour types, such as gastrointestinal stromal tumours, seminoma/dysgerminoma, acute myelogenous leukaemia, neuroblastoma, Ewing's sarcoma, mast cell disorders, and small-cell or large-cell neuroendocrine carcinoma of the lungs (19).

The development of targeted therapy with protein kinase inhibitors has demonstrated clinical safety and efficacy for several cancer types. Thus, overexpressing of CD117 would 
Table I. Analysis of CD117 expression.

\begin{tabular}{llc}
\hline Score & Expression & Staining pattern \\
\hline 0 & Negative & No staining, or membranous staining in fewer than 10\% of tumour cells. \\
$1+$ & Negative & Faint barely perceptive membranous staining detected in more than $10 \%$ of tumour cells. \\
& The cells are only stained in part of the membrane. \\
$2+$ & Positive & Weak to moderate complete membranous staining in more than $10 \%$ of the tumour cells. \\
$3+$ & Positive & Strong complete membranous staining in more than $10 \%$ of tumour cells.
\end{tabular}

enable the use of inhibitors such as imatinib mesylate and sorafenib as treatment option for oesophageal carcinoma (20-23).

CD117 has not yet been assessed in oesophageal cancer in a Brazilian population, although it has a high prevalence among southern Brazilian states. Therefore, the aim of the present study was to evaluate the immunohistochemical expression of CD117 in SCCO, in an attempt to determine whether this kinase may be expressed in our hospital cases and to see whether it may allow any blocking therapy in the future.

\section{Materials and Methods}

Patients. In this preliminary study, 27 cases of SCCO were retrospectively studied randomly selected among those patients who underwent surgical resection at the University Attached Hospital, Faculty of Medicine, Rio Grande do Sul Federal University, Porto Alegre, RS, southern Brazil between 2006 and 2010. Clinical data were noted from patient records and biopsy-proven SCCO was obtained by endoscopic examination prior to any treatment. As a control group, 10 tissue specimens of oesophageal mucosa from healthy volunteers were studied. The study was performed by the Southern Surgical Oncology Group of the Post-Graduate Program of Surgery, Faculty of Medicine after approval by the Institutiona Review Board of the Hospital de Clínicas de Porto Alegre University Attached Hospital (HCPA-UFRGS).

CD117 immunohistochemistry. Tissue sections (4-mm-thick) were deparaffinised and rehydrated in water. Sections were rinsed with phosphate-buffered saline and incubated with a monoclonal antibody anti-CD117 (DakoCytomation, San Diego, CA, USA) diluted at 1:50. To determine the antibody reactivity, the avidinbiotin peroxidase complex (ABC method; LSAB Kit; DakoCytomation) was used (Figure 1). Endogenous peroxidase activity was blocked with $0.3 \%$ hydrogen peroxide for $15 \mathrm{~min}$. Following incubation, all samples were rinsed with phosphatebuffered saline and were rinsed and counterstained with Harris haematoxylin. The procedure was carried out at the Pathology Department of the University Hospital. As positive controls for immunohistochemical reaction, interstitial cells of Cajal known to express CD117 were used (Figure 2). All immunostaining reactions were evaluated and double-checked by the same pathologist unaware of patient identity, tumour condition or clinical outcome.

The slides were analysed following a score of 0 to $3+$, where 0 meant completely negative; $1+$ weakly positive; $2+$ moderately
Table II. Clinical and pathological features of the patient population.

\begin{tabular}{lcc}
\hline Feature & $\mathrm{n}$ & Percent \\
\hline Gender & & \\
$\quad$ Male:female & $21: 6$ & $78: 22$ \\
Tumour site & & \\
$\quad$ Middle third & 10 & 37 \\
$\quad$ Distal third & 17 & 63 \\
Histological type & & \\
$\quad$ Well-differentiated & 3 & 11 \\
$\quad$ Moderately differentiated & 22 & 82 \\
$\quad$ Poorly differentiated & 2 & 7 \\
7th Edition AJCC Staging & & \\
I & 1 & 4 \\
IIB & 5 & 18 \\
$\quad$ III & 21 & 78 \\
CD117 expression & & \\
Positive & 4 & 15 \\
$\quad$ Negative & 23 & 85 \\
\hline
\end{tabular}

positive; $3+$ strongly positive (Table I). Only staining scored $2+$ and $3+$ at membranous sites (no cytoplasmic staining considered) were regarded as positive.

Qualitative data were described as mean, median, minimum and maximum values, and standard deviation. Percentages and frequencies were used for categorical variables. The association between CD117 overexpression and clinical and pathological features was carried out using the chi-square test. Deaths unrelated to oesophageal cancer were not considered for overall survival analysis calculated from treatment onset. The statistical significance level $(\alpha)$ was set at 0.05 .

\section{Results}

Twenty-one $(78 \%)$ patients were male. The median age was 58 years and ranged from 36 to 77 years.

Tumour grade was considered according to the World Health Organisation classification (24) as follows: Three (11\%) patients presented well-differentiated tumour, $22(82 \%)$ moderately differentiated and two $(7 \%)$ poorly differentiated (Table II). The immunohistochemical reaction produced by the anti-CD117 antibody was considered positive in only four cases $(15 \%)$ out of 27 tumours and in none of the controls. 


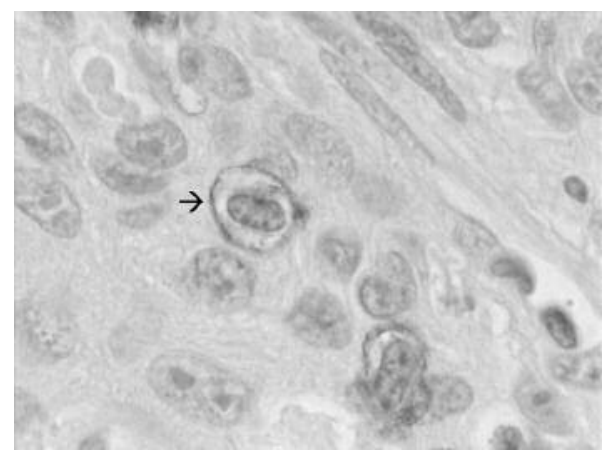

Figure 1. A representative case of an oesophageal tumour positive for CD117 expression (immunohistochemical, 400x magnification).

The depth of invasion, according to the seventh edition of the American Joint Committee on Cancer classification (25), varied; the majority of the cases were of stage III $(n=21$; $78 \%$ ). The median (SD) overall survival rate was 21 (8) months, ranging from 2 to 72 months. Survival was significantly lower for those with advanced pT stage $(p \leq 0.001)$ and lymph node $(p \leq 0.001)$ involvement. However, association with CD117 fail to be demonstrated due to the small number of positive cases of the subgroups in this sample.

\section{Discussion}

SCCO is still a disease of poor prognosis. Many therapies, such chemotherapy and radiotherapy, have been combined with surgery in an attempt to change this scenario, yet no clear improvement in survival has been reported. The outcome of patients with advanced disease remains poor, and 5 -year survival rates rarely exceed $10 \%$ in Western countries (26). SCCO is highly prevalent in Southern Brazil and the overall mortality rate in this region for oesophageal cancer was 14.0 and 4.5 per 100,000 inhabitants for men and women respectively in 2014-2015 (4).

The multiple stages of oesophageal carcinogenesis have been histologically defined. It has been established that oesophageal carcinoma usually evolves through a series of progressively severe histopathological changes which involves dysplasia of the epithelium, carcinoma in situ and, finally, invasive tumour (27). Based on the concept that precancerous cells may have early alterations at a molecular level, identification of new potential biomarkers might play an important role in detection of high-risk lesions for malignant transformation and early diagnosis of $\operatorname{SCCO}(13,28)$.

Immunohistochemical expression of gene by-products has become an easy, simple and very practical and widespread method for determining the involvement of a number of factors in paraffin-embedded samples from a wide range of

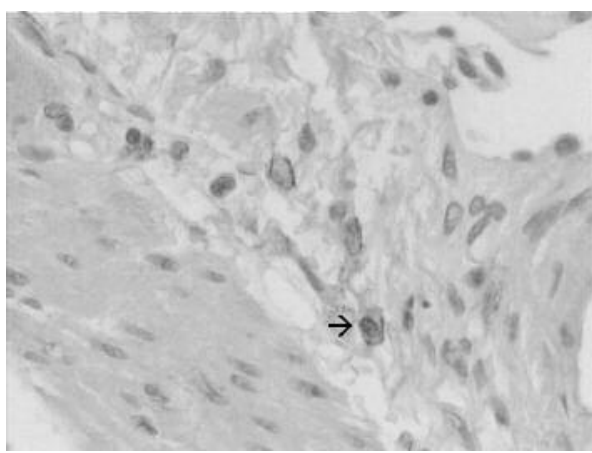

Figure 2. A Cajal cell expressing CD117, used as a positive control (immunohistochemical, 400× magnification).

tissues, including tumours. It is therefore more routinely used to study the expression of new potential therapeutic targets and to determine which patients are the most likely to respond to these specific therapies (29).

The improvements achieved in molecular biology certainly favour appropriate methods for molecular screening, and may result in early diagnosis, allowing curative therapy. CD117, a trans-membrane tyrosine kinase receptor, is expressed in a large variety of human neoplasms. Little, however, is known about the prevalence and clinical implications of CD117 in SCCO, with few studies reported (30).

CD117 expression in malignant tumours plays an important role for cancer treatment since it is one of the targets of the tyrosine kinase inhibitors. The tyrosine kinase inhibitor imatinib was initially shown to be effective in the treatment of chronic myeloid leukaemia, in which it targets the kinase function of the breakpoint cluster region-Abelson proto-oncogene (BCR-ABL) fusion protein-Philadelphia chromosome. Subsequently, significant treatment responses were also reported in patients with advanced CD117-positive gastrointestinal stromal tumours. It has been suggested that the response rate to imatinib may be particularly high in CD117-expressing tumours that also harbour activating CD117 mutations (23).

Went et al. studied the prevalence of CD117 expression in more than 3,000 human tumours from 120 different tumour types by immunohistochemistry in a tissue microarray set. The epidemiologically most important CD117-positive tumours included gastrointestinal stromal tumours (100\%), seminoma (84\%), malignant melanoma (36\%), large-cell (17\%) and small-cell carcinoma of the lungs (7\%). For SCCO, immunoreactivity was documented in only two out of 34 cases $(5 \%)$ (31).

Zhang et al. studied the expression of CD117 in tumour tissue, surrounding-tumour tissue and normal tissue of 50 specimens of either squamous or adenocarcinoma of 
oesophageal tumours. The strong expression rate was low in tumour, para-tumour, and normal tissues (4\%, 4\%, and 12\%), respectively (21). Patients in that series similarly presented with tumours of the middle and lower oesophagus. No statistically significant differences were noted for CD117 expression and differentiation, depth of invasion, lymph node metastasis or stage and these findings are in agreement with those results from Zhang et al. (21).

Gilbault et al. showed expression of CD117 to be very rare in SCCO finding it in fewer than $3 \%$ of the cases (3/107). Like our cases, the use of external or internal positive controls (positive mastocytes in cancer stromal reaction for CD117) during immunohistochemical procedures ruled out the possibility of false-negative reactions (29), which corroborates those findings of lack of expression of CD117 for alternative associated target therapy.

In the present study, overexpression of CD117 was found in $15 \%$ of cases, which is almost 4 -fold higher than the expression reported by Zhang et al. for both squamous carcinoma and adenocarcinoma. This difference may be explained by the fact that to date, this is the first study addressing patients with cancer from an area with a high incidence of SCCO, and that tumours in this series were of slightly more advanced stage (66\% vs. $78 \%)$ as compared to the series of Zhang et al. (21).

Our results suggest that CD117 is overexpressed at a low rate in tumour tissue, corroborating previous findings. Therefore, failure to demonstrate overexpression of CD117 in SCCO may be due to a lack of control of the cell cycle in these tumours. However, this low expression was not significantly related to any prognostic feature and may not justify target therapy against CD117, such as c-KIT inhibitors.

\section{Acknowledgements}

This work was partially granted by the Research Fund from HCPA University Hospital and the Developing Program for Post-graduate Institutions (PRODOC-CAPES 2003-2007).

\section{References}

1 Ferlay J, Soerjomataram I, Dikshit R, Eser S, Mathers C, Rebelo M, Parkin DM, Forman D and Bray F: Cancer incidence and mortality worldwide: sources, methods and major patterns in GLOBOCAN 2012. Int J Cancer 136(5): 359-386, 2015.

2 Jemal A, Bray F, Center MM, Ferlay J, Ward E and Forman D: Global cancer statistics. CA Cancer J Clin 61(2): 69-90, 2011.

3 Ribeiro U Jr., Posner MC, Safatle-Ribeiro AV and Reynolds JC: Risk factors for squamous cell carcinoma of the oesophagus. $\mathrm{Br}$ J Surg 83(9): 1174-1185, 1996.

4 Brasil. Ministério da Saúde. Secretaria de Atenção à Saúde SAS. Instituto Nacional do Câncer José Alencar Gomes da Silva. Coordenação de Prevenção e Vigilância: Estimate/2018 - Cancer Incidence in Brazil. Rio de Janeiro: INCA, 2017. http:// www.inca.gov.br/estimativa/2018/index.asp.
5 Samarasam I: Esophageal cancer in India: Current status and future perspectives. Int J Adv Med Health Res 4(1): 5-10, 2017.

6 Tew WP, Kelsen DP and Ilson DH: Targeted therapies for esophageal cancer. Oncologist 10(8): 590-601, 2005.

7 Lyer R, Wilkilson N, Demmy T and Javle M: Controversies in the multimodality management of locally advanced esophageal cancer: evidence-based review of surgery alone and combinedmodality therapy. Ann Surg Oncol 11(7): 665-673, 2004.

8 Moreira LF, Naomoto Y, Kamikawa Y, Hamada M and Orita K: Assessment of apoptosis in oesophageal carcinoma preoperatively treated by chemotherapy and radiotherapy. Anticancer Res 15(2): 639-644, 1995.

9 Bedenne L, Michel P, Bouché O, Milan C, Mariette C, Conroy T, Pezet D, Roullet B, Seitz JF, Herr JP, Paillot B, Arveux P, Bonnetain $\mathrm{F}$ and Binquet $\mathrm{C}$ : Chemoradiation followed by surgery compared with chemoradiation alone in squamous cancer of the esophagus: FFCD 9102. J Clin Oncol 25(10): 1160-1168, 2007.

10 Stahl M, Stuscke M, Lehamann N, Meyer HJ, Walz MK, Seeber S, Klump B, Budach W, Teichmann R, Schmitt M, Schmitt G, Franke C and Wilke H: Chemoradiation with and without surgery in patients with locallly advanced squamous cell carcinoma of the esophagus. J Clin Oncol 23(10): 23102317, 2005.

11 Urschel JD, Vasan H: A meta-analysis of randomized controlled trials that compared neoadjuvant chemoradiation and surgery to surgery alone for resectable esophageal cancer. Am J Surg 185(6): 538-543, 2003.

12 Urba SG, Orringer MB, Turrisi A, Iannettoni M, Forastiere A, Strawderman M: Randomized trial of preoperative chemoradiation versus surgery alone in patients with locoregional esophageal carcinoma. J Clin Oncol 19(2): 305-313, 2001.

13 Fagundes RB, Melo CR, Pütten AC, Moreira LF and de Barros SG: P53 immunoexpression: An aid to conventional methods in the screening of precursor lesions of squamous esophageal cancer in patients at high-risk? Cancer Detect Prev 29(3): 227232, 2005.

14 Montesano R, Hollstein M and Hainaut P: Genetic alterations in esophageal cancer and their relevance to etiology and pathogenesis: a review. Int J Cancer 69(3): 225-35, 1996.

15 Jankowski J, Jankowski R and Wormsley KG: Oesophageal carcinoma: the need for screening. Eur J Cancer Prev 2(1): 5$12,1993$.

16 Lammie A, Drobnjak M, Gerald W, Saad A, Cote R and Cordon-Cardo C: Expression of c-KIT and KIT ligand proteins in normal human tissues. J Histochem Cytochem 42(11): 14171425, 1994.

17 Matsuda R, Takahashi T, Nakamura S, Sekido Y, Nishida K, Seto M, Seito T, Sugiura T, Ariyoshi Y, Takahashi T and Ueda R: Expression of c-KIT protein in human solid tumors and in corresponding fetal and adult normal tissues. Am J Pathol 142(1): 339-346, 1993.

18 Poole DP, Van Nguyen T, Kawai M and Furness JB: Protein kinases expressed by interstitial cell of Cajal. Histochem Cell Biol 121(1): 21-30, 2004.

19 Dagher R, Cohen M, Williams G, Rothmann M, Gobburu J, Robbie G, Rahman A, Chen G, Staten A, Griebel D and Pazdur $\mathrm{R}$ : Approval summary: Imatinib mesylate in the treatment of metastatic and/or unresectable malignant gastrointestinal stromal tumors. Clin Cancer Res 8(10): 3034-3038, 2002. 
20 Johnson JR, Bross P, Cohen M, Rothmann M, Chen G, Zajicek A, Gobburu J, Rahman A, Staten A and Pazdur R: Approval summary: Imatinib mesylate capsules for treatment of adult patients with newly diagnosed Philadelphia chromosomepositive chronic myelogenous leukemia in chronic phase. Clin Cancer Res 9(6): 1972-1979, 2003.

21 Zhang X, Rong TH, Zhang Y, Long H, Fu JH, Ling P, Zhang LJ, Yang MT, Zeng CG, Ma GW, Su XD, Li XD, Wang JY, Wen ZS and Zhao JM: Expression and significance of c-KIT and plateletderived growth factor receptor-beta (PDGFRbeta) in esophageal carcinoma. Chinese J Cancer 25(1): 92-95, 2006.

22 Wilhelm SM, Adnane L, Newell P, Villanueva A, Llovet JM and Lynch M: Preclinical overview of sorafenib, a multikinase inhibitor that targets both RAF and VEGF and PDGF receptor tyrosine kinase signaling. Mol Cancer Ther 7(10): 3129-3140, 2008.

23 Babaei MA, Kamalidehghan B, Saleem M, Huri HZ and Ahmadipour F: Receptor tyrosine kinase (c-KIT) inhibitors: a potential therapeutic target in cancer cells. Drug Des Devel and Ther 10: 2443-2459, 2016.

24 Montgomery E, Field JK and Boffetta P: Squamous cell carcinoma of the oesophagus. In: Bosman FT, Carneiro F, Hruban RH and Theise ND: WHO Classification of Tumours of the Digestive System, Fourth Edition. Lyon: International Agency for Research on Cancer 3: 18-24, 2010.

25 Edge SB, Byrd DR, Compton CC, Fritz AG, Greene FL and Trotti A: AJCC Cancer Staging Manual. Seventh Edition. New York, Springer, 2010
26 Ilson DH: Esophageal cancer chemotherapy: recent advances. Gastrointest Cancer Res 2(2): 85-92, 2008.

27 Jain S and Dhingra S: Pathology of esophageal cancer and Barrett's esophagus. Ann Cardiothorac Surg 6(2): 99-109, 2017.

28 Contu SS, Contu PC, Damin DC, Fagundes RB, Bevilacqua F, Rosa AS, Prolla JC and Moreira LF: pRB expression in esophageal mucosa of individuals at high risk for squamous cell carcinoma of the esophagus. World J Gastroenterol 13(11): 17281731, 2007.

29 Gibault L, Metges JP, Conan-Charlet V, Lozac'h P, Robaszkiewicz M, Bessaguet C, Lagarde N and Volant A: Diffuse EGFR staining is associated with reduced overall survival in locally advanced oesophageal squamous cell cancer. Br J Cancer 93(1): 107-115, 2005.

30 Goscinski MA, Larsen SG, Giercksky KE, Nesland JM and Suo Z: PDGFR- $\alpha$ and CD117 expression pattern in esophageal carcinomas. Anticancer Res 35(7): 3793-3799, 2015.

31 Went PT, Dirnhofer S, Bundi M, Mirlacher M, Schraml P, Mangialaio S, Dimitrijevic S, Kononen J, Lugli A, Simon R and Sauter G: Prevalence of KIT expression in human tumors. J Clin Oncol 22(22): 4514-4522, 2004.
Received May 4, 2018

Revised May 30, 2018

Accepted June 1, 2018 